\title{
The Diffrentiation of the Angles of Eustachian Tubes In the Patient Chronic Suppurative Otitis Media With and without Cholesteatoma
}

\author{
Rissa Ardika Nasution, Devira Zahara, Askaroellah Aboet \\ Departemen Telinga, Hidung, Tenggorok, Kepala dan Leher, \\ Fakultas Kedokteran Universitas Sumatera Utara, Medan, Indonesia
}

\begin{abstract}
Background: Chronic Suppurative Otitis Media (CSOM) is one of the major health problems found in many populations in the world and a cause of high morbidity and high mortality. However, there is no single theory that explains how and why chronic otitis media occurs. There are many studies on the function of Eustachian tube. However, the role of the Eustachian tube angle and the relationship with the occurrence of CSOM has not been widely studied. This study aimed to evaluate the mean of Eustachian tube angle and to examine the diffrentiation between angle of Eustachian tube in Chronic Suppurative Otitis Media (CSOM) patient with and without cholesteatoma.

Subjects and Methods: This research is a case-control study. Study group consist of 27 patients of CSOM with cholesteatoma and 27 patients of CSOM without cholesteatoma included as controlling. All patients are examined by using CT temporal and measured the angle of Eustachian tube using Multiplanar Reconstruction (MPR) technique on osirix program. The data was analyzed using independent T test

Results: The mean of the Eustachian tube angle in CSOM with cholesteatoma in female patients was $28.69^{\circ}$ and male $27.78^{\circ}$ whereas in the CSOM group without cholesteatoma in female patients was $33.81^{\circ}$ and men $31.87^{\circ}$. The mean of Eustachian tube angle in CSOM patients with cholesteatoma is $28.22^{\circ}$ and CSOM without cholesteatoma is $33.00^{\circ}$. In independent $\mathrm{T}$ test, the result showed significant differentiation $(\mathrm{p}=0.001)$ between the angle of Eustachian tube in patients CSOM with and without cholesteatoma.

Conclusion: The advance of technology makes easier to measure of Eustachian tube angle. In men found that the Eustachian tube angle is more horizontal than women. There is diffrence between the angle of the Eustachian tube with the occurrence of cholesteatoma in CSOM.
\end{abstract}

Keywords: angle of Eustachian tube, CSOM

\section{Correspondence :}

Rissa Ardika Nasution. RSUP H. Adam Malik, Medan. FK USU, Jln. Sembada Pasar V no. 27 P. Bulan Medan. Email: nrissaardika@yahoo.com. Mobile: 082277767660.

\section{BACKGROUND}

Chronic Suppurative Otitis Media (CSOM) is one of the major health problems found in many populations in the world and a cause of high morbidity and high mortality. However, there is no single theory that explains how and why chronic otitis media occurs. Beside genetic and environmental factors, craniofacial anatomy is also considered to play a role in the occurrence of chronic otitis media. The size of the mastoid and Eustachian tube are craniofacial anatomy which related in the occurrence of the CSOM disease. There are 
Indonesian Journal of Medicine (2017), 2(1): 73-78

https://doi.org/10.26911/theijmed.2016.01.03.08

many studies on the function of Eustachian tube. However, the role of the Eustachian tube angle and the relationship with the occurrence of CSOM has not been widely studied (Sirikci, 2001).

Eustachian tube in children is shorter and more horizontal than in adults. In adults, the tube forms an angle of $30-40^{\circ}$ with a horizontal plane, whereas in children only form an angle of $10^{\circ}$. Eustachian tube angle will be the same as adults at 7-8 years of age. A more horizontal angle of the Eustachian tube causes otitis media to occur frequently in children. Recurrent acute otitis media (AOM) or otitis media effusions (EOM) that last a long time in childhood will cause the CSOM in adulthood (Dinc, 2015).

Eustachian tube plays an important role in maintaining the physiology of the middle ear. Eustachian tube has three functions: ventilation, protection, and cleaning of the middle ear. The length and angle of the Eustachian tube determines the possibility of preventing nasopharyngeal reflux into the middle ear. Eustachian tube dysfunction is a pathophysiological mechanism underlying the formation of retraction pocket and cholesteatoma. Tympanic pocket membrane retraction is characterized by partial collapse of the mesotimpani or epitimpani cavities. Cholesteatoma destroys the temporal bone and adjacent bone structure which cause various complications (Dinc, 2015).
On examination of CT temporal scans on 210 patients CSOM concluded there was a significant relationship between patients with CSOM type cholesteatoma with lower Eustachian tube angle. A more horizontal Eustachian tube angle will cause Eustachian tube dysfunction and impaired clearance in the middle ear (Aksoy, 2016)

Research on the anatomy of Eustachian tubes involving radiology is still less. The multiplanar reconstruction technique (MPR) is one of several new imaging techniques in computed tomography (CT) that makes the anatomical features of the Eustachian tube more pronounced. By using multiplanar reconstruction techniques, the image can be adjusted as desired by changing the angle of the plane every 0.5 degrees and changing the station every 1 millimeter (Takasaki, 2007).

This study aims to examine the diffrentiation between angle of Eustachian tube in CSOM patient with and without cholesteatoma. The angle of the Eustachian tube will be measured using multiplanar reconstruction techniques. Angle of the ET was defined as the angle of a straight line from the pharyngeal orifice to the tympanic orifice of the ET against Reid's standard plane, which is difined as the plane connecting the infraorbita margins with the upper margins of the external auditory meatus (Takasaki, 2007).

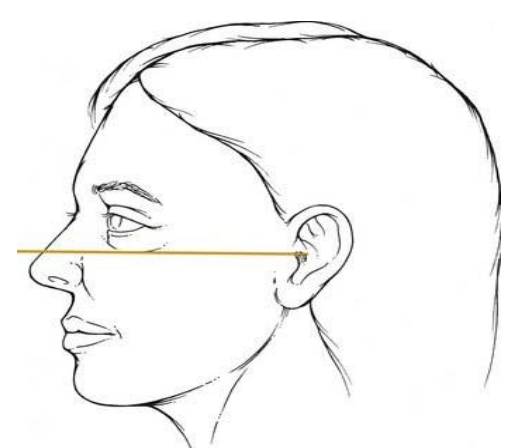

Figure 1. Reid horizontal plane (infraorbita meatal line) 


\section{SUBJECTS AND METHOD}

This research is analytic with case control approach. The study was conducted on outpatient Otology Division H. Adam Malik Medan General Hospital and for examination of temporal CT scan performed at the Department of Radiology RSUP H. Adam Malik Medan in January 2015- March 2017.

The subjects of the study were 54 people which consist of 27 people in the cholesteatoma group and 27 people in the group without cholesteatoma taken with consecutive sampling. Sample selection criteria include inclusion criteria patients CSOM with and without cholesteatoma which doing treatment in the Otology Division H. Adam Malik Medan General Hospital who had performed a temporal CT scan with $1 \mathrm{~mm}$ slice thickness and surgery tompanomastoidectomy. Exclusion criteria in this study were patients $<8$ years old and there is a damage on CT scan patients so that Eustachian tube angle can not be measured.

Patients who have been diagnosed under anamnesis history, otoscopy examination and CT scan, if the results of CT scan found cholesteatoma and then proved by the presence of cholesteatoma on timpanomastoidectomy surgery. The angle of the Eustachian tube was measured using the program osirix lite application. As explained in the introduction, Angle of the ET was defined as the angle of a straight line from the pharyngeal orifice to the tympanic orifice of the ET against Reid's standard plane, which is difined as the plane connecting the infraorbita margins with the upper margins of the external auditory meatus (Takasaki, 2007).

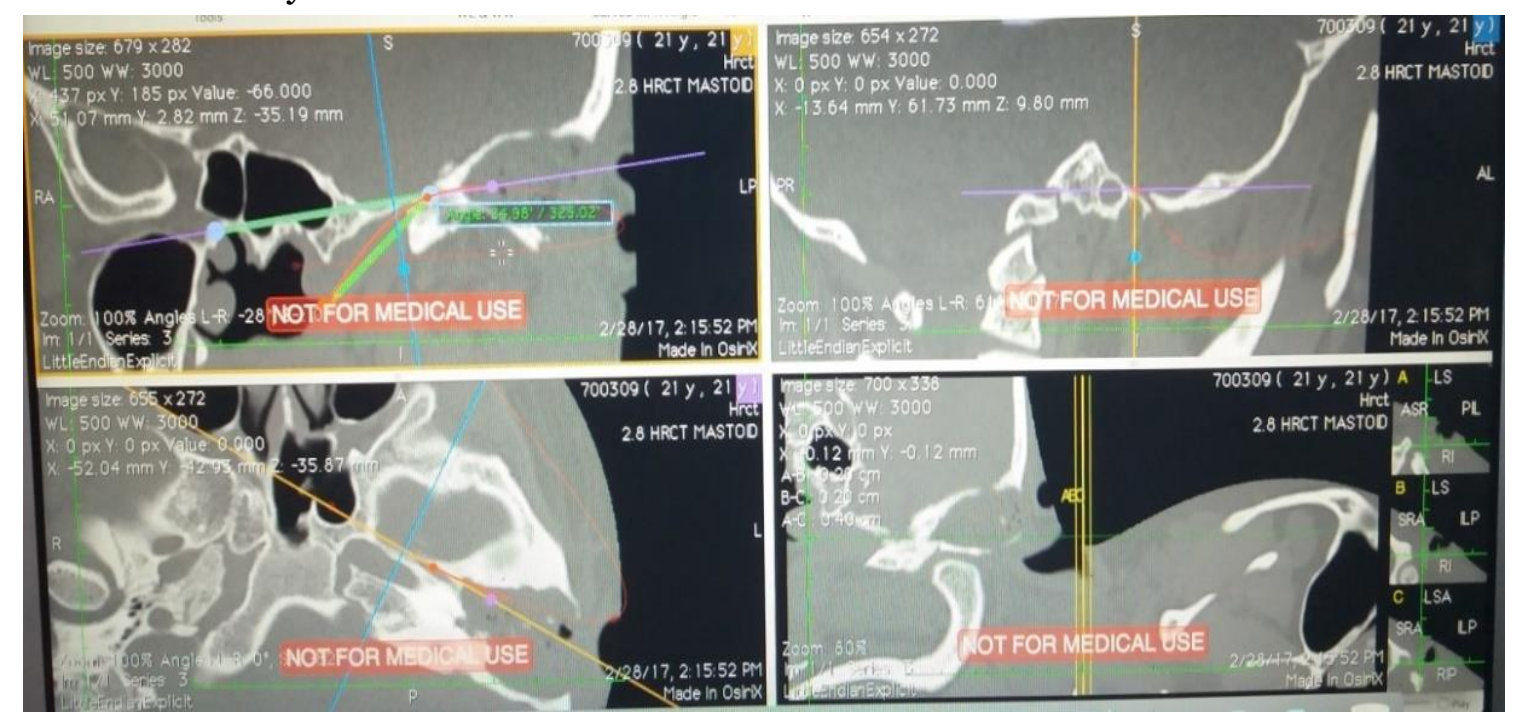

Figure 2. MPR Technique on Osirix Lite Program

Distribution of data of the angle of Eustachian tube was analyzed using Shapirowilk test. In this study the data is normally distributed ( $p>0.05)$. Furthermore, the relationship of the angle of the Eustachian tubes in the patients with CSOM with cholesteatoma was analyzed by independent $\mathrm{T}$ test.

\section{RESULTS}

Table 1 shows the mean angle of the Eustachian tubes of patients with CSOM without cholesteatoma in women was $33.81^{\circ}$ and men $31.87^{\circ}$ whereas in patients with CSOM cholesteatoma, women $28.69^{\circ}$ and men $27.78^{\circ}$.

Large range of Eustachian tube angle in the CSOM group with cholesteatoma, 
women between $21^{\circ}-36^{\circ}$ and men $22^{\circ}-40^{\circ}$ whereas in the CSOM group without cholesteatoma, $29^{\circ}-39^{\circ}$ women and $24^{\circ}-40^{\circ}$ males.

Table 2 shows the large mean angle of the Eustachian tube of patients with CSOM without cholesteatoma at the onset since childhood is $34.01^{\circ}$ and after childhood $31.60^{\circ}$ whereas in patients with $\mathrm{CSOM}$ cholesteatoma, onset since childhood $27.77^{\circ}$ and after childhood $30.20^{\circ}$.

Table 1. The mean of the angle of Eustachian Tube based on gender

\begin{tabular}{lcccccc}
\hline \multirow{2}{*}{ Gender } & \multicolumn{5}{c}{ Angle of Eustachian Tube (o) } \\
\cline { 2 - 7 } & \multicolumn{3}{c}{ Cholesteatoma (-) } & \multicolumn{3}{c}{ Cholesteatoma (+) } \\
\cline { 2 - 7 } & $\mathbf{n}$ & mean & SD & n & Mean & SD \\
\hline Female & 11 & 33.81 & 3.31 & 13 & 28.69 & 5.39 \\
Male & 16 & 31.87 & 4.64 & 14 & 27.78 & 4.80 \\
\hline
\end{tabular}

Tabel 2. The diffrentiation of the mean of the angle of eustachian tube with CSOM with and without Cholesteatoma

\begin{tabular}{lccc}
\hline \multirow{2}{*}{ CSOM } & \multicolumn{3}{c}{ Angle of Eustachian Tube (o) } \\
\cline { 2 - 4 } & mean & SD & p \\
\hline With Cholesteatoma & 28.22 & 4.25 & 0.001 \\
Without Cholesteatoma & 33.00 & 5.01 & \\
\hline
\end{tabular}

In the Shapirowilk test, $\mathrm{p}$ value was found for CSOM group with cholesteatoma and CSOM group without cholesteatoma with normal distribution that is $\mathrm{p}=0.900$ and $\mathrm{p}=0.755$. Furthermore, $\mathrm{T}$ independent test and statistically significant difference $\mathrm{p}$ $=0.001$.

\section{DISCUSSION \\ 1. The mean of the angle of Eusta- chian tubes in otitis media patients supuratif chronic based on gender}

CSOM sufferers in Hasan Sadikin Hospital, Bandung is higher in men (53\%) than women (47\%) (Fasyah, 2016). The same was also reported in 119 patients who went to the hospital treatment of RSUP H. Adam Malik Medan from 2006-2010 obtained the highest incidence in male patients is 64 people and 55 women (Asroel, 2013).

Srivastava (2010) in India found the highest incidence of CSOM in men compared to women, $56.3 \%$ and $43.7 \%$ of 110 patients.

Craniofacial anatomy in men and women has differences. This is evidenced by Avci's research (2014) in Turkey that compared craniofacial anatomy in 60 normal people consisting of 30 women and 30 men. The results of his study found that men have a larger corner of Eustachian tubes are more horizontal and Eustachian tube larger than women. Similarly, the length of the mastoid cavity, the distance of intercoclea and thickness of Eustachian tube bone in men is bigger than women.

The same results were also obtained in this study, where the angle of Eustachian tube in men is more horizontal than in women and the number of patients with CSOM in men more than women. Dinc (2015) in Turkey reported the Eustachian tube angle was significantly more horizontal in men than in women. This causes more men suffer from CSOM with cholesteatoma. The more horizontal angle of the Eustachian tube causes Eustachian tube dysfunction and triggers the formation of retraction pockets which subsequently becomes the will of cholesteatoma. 


\section{The diffrentiation of the mean of the angle of Eustachian tube with CSOM with and without Cholesteatoma}

Aksoy (2016) in Turkey conducted a study of Eustachian tube angle on 210 patients who performed a temporal CT scan and concluded that there was a significant relationship between CSOM patients with cholesteatoma with a more horizontal Eustachian tube angle.

A more horizontal angle of the Eustachian tube will cause Eustachian tube dysfunction and interference with the middle ear. Experiments in experimental animals in clinical studies have proven that Eustachian tubal dysfunction is involved in the pathogenesis of middle ear disease. When the tensor veli palatini muscle is disrupted, the opening of Eustachian tube will also be disrupted. This causes negative pressure on the middle ear and effusion of the middle ear. In an experiment, excision of some tensor veli palatini muscles in the pterigoid hamulus in the palate caused negative pressure in the middle ear and accompanied by the occurrence of middle ear effusion. Total excision results in underpressures in the middle ear followed by persistent middle ear effusion (Bluestone, 2007).

Chronic inflammation or inflammation is known to cause changes in metastasis of columnar epithelium to stratified squamous epithelium. Squamous epithelial invasion of the ear canal or the outer surface of the tympanic membrane into the middle ear via marginal perforation or perforation causes retraction of pocket. Furthermore in this place formed a matrix of cholesteatoma in the form of epithelial cells that are piled on the spot (Meyer, Strunk \& Lambert, 2006; Chole \& Nason, 2009).

This study proved that there was statistically significant difference $(\mathrm{p}<0.05)$ of the mean Eustachian tubular angle in CSOM patients with and without cholesteatoma using T-independent test. Thus the hypothesis in this study is accepted.

This study proved that there was a statistically significant difference $(\mathrm{p}<0.05)$ of the mean of Eustachian tube angle in CSOM patients with and without cholesteatoma using a T-independent test. The research is expected to open the insight into research. That utilizes technological advance especially in the field of radiology and can be the foundation of the theory for further research.

\section{REFERENCE}

Aboet A (2007). Radang telinga tengah menahun, Pidato Pengukuhan Jabatan Guru Besar Tetap Bidang Ilmu Kesehatan Telinga Hidung Tenggorok Bedah Kepala Leher, FK USU, Medan.

Aksoy S, Sayin I, Yazici ZM, Kayhan FT, Karahasanoglu A, Hocaoglu E, Inci E (2016). 'The evaluation of the angles of Eustachian tubes in the patients with chronic otitis media on the temporal computerized tomography', Nigerian Journal of Clinical Practice (19): 318-22.

Avci S, Ergun T, Aydin E, Kansu L (2015). Sex differences in adult craniofacial parameters, Surg Radiol Anat, 37: 1069-78.

Bluestone CD (2007). 'Physiology, Pathophysiology, and Pathogenesis', Otitis media in infant and children, $\mathrm{BC}$ Decker, Hamilton, 41-72.

Chole RA, Nason R (2009). Chronic otitis media and cholesteatoma, Ballenger's Manual of Otorhinology Head and Neck Surgery, BC Decker, Connecticut, 217-27.

Dinc AE, Damar M, Ugur MB, Ilker I, Elicora SS, Biskin S, Tutar H (2015). 
'Do the angle and length of the Eustachian tube influence the development of chronic otitis media?', The Laryngoscope Journal (125): 2187-92.

Meyer TA, Strunk TL, Lambert PR (2006). Cholesteatoma, Head \& Neck SurgeryOtolaryngology, Lippincott \& Wilkins, Williams Texas, 2094-112.

Sirikci A, Bayazit YA, Bayram M, Kanlikoma M (2001). 'Significance of the auditory tube angle and mastoid size in chronic ear disease', Surg Radiol
Anat, 23: 91-5.

Takasaki K, Takahashi H, Miyamoto I, Yoshida H, Yamamoto FT, Enatsu K, Kumagami H (2007). Measurement of angle and length of the eustachian tube on computed tomography using the multiplanar reconstruction technique. Laryngoscope journal, 117(7): 1251-4.

Zimbler MS (2015), Aesthetic facial analysis. Cummings Otolaryngology Head \& Neck Surgery,19: 269-80. 